\title{
Origem Anômala das Coronárias: Tronco Único
}

\section{Anomalous Origin of the Coronary Arteries: Single Trunk}

\author{
Marcelo Abramoff Continentino e João Luis G. da Silva \\ Hospital Maternidade Frei Galvão; Instituto Dante Pazzanese de Cardiologia, São Paulo, SP - Brasil
}

\section{Introdução}

Paciente de 68 anos, assintomático, foi submetido à tomografia computadorizada cardíaca. Observou-se tronco único em seio de Valsalva direito que se bifurcava em coronárias direita e esquerda. Após trajeto entre as artérias pulmonar e aorta, esta dava origem às artérias descendente anterior e circunflexa.
Com o advento de novos exames de imagem, o diagnóstico de anomalias coronárias tem sido mais frequente. A maioria dos casos não apresenta repercussão, porém alguns podem levar à isquemia miocárdica ou morte súbita. O trajeto entre as artérias aorta e pulmonar ("maligno") pode levar à compressão arterial. No caso descrito, o paciente apresentava esse trajeto, porém sem sintomas.

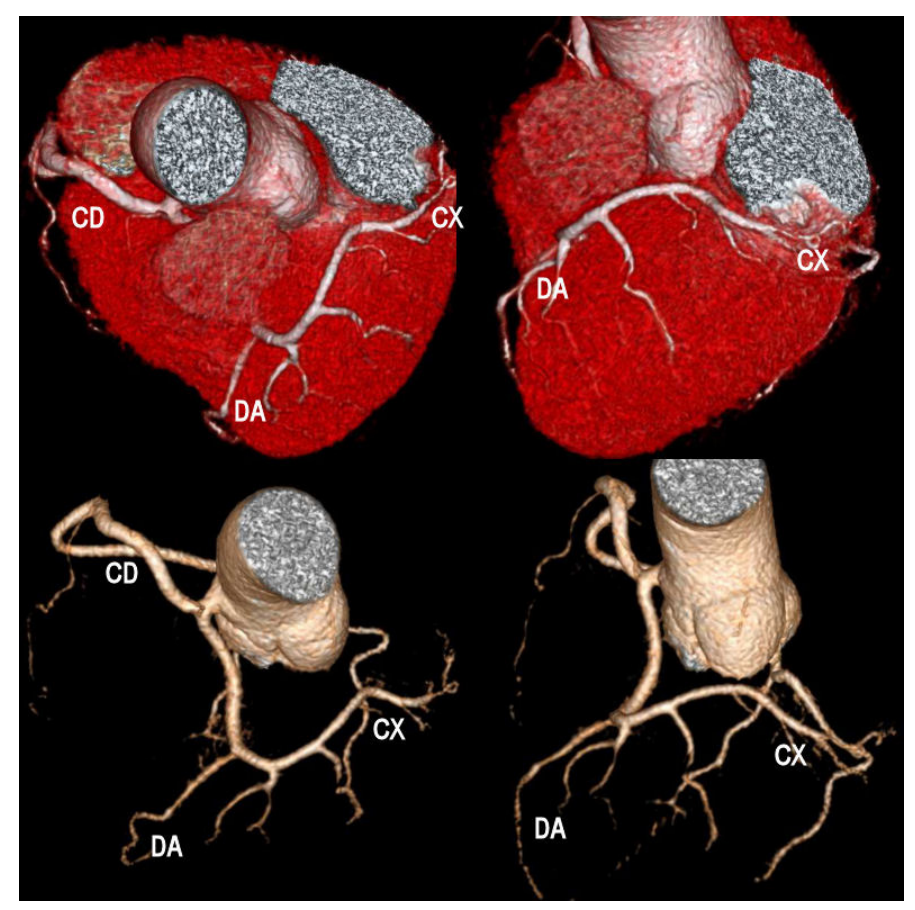

Fig 1 - Reconstrução tridimensional da anatomia coronária DA - descendente anterior, $C X$ - circunflexa, $C D$ - coronária direita.

\section{Palavras-chave}

Seio de Valsalva, vasos coronários/lesões, origem anômala das coronárias, tronco único, tomografia computadorizada. 